\title{
RANCANG BANGUN APLIKASI CLOUD STORAGE DENGAN ANGGULAR DAN FIREBASE BERBASIS ANDROID
}

\author{
Fathurrahman Kurniawan Ikhsan ${ }^{\# 1}$, Fatimah Fahurian ${ }^{* 2}$, Aliy Hafiz ${ }^{\# 3}$ \\ Fakultas Komputer \\ Universitas Mitra Indonesia \\ Jln. Z.A. Pagar Alam No.07 Gedongmeneng Bandar Lampung 35142 \\ Telp. (0721) 701418 Fax.(0721) 788960 Web. www.umitra.ac.id \\ ${ }^{1}$ Fathurrahman@umitra.ac.id \\ ${ }^{2}$ fatimah fahurian@umitra.ac.id \\ AMIK Dian Cipta Cendikia \\ ${ }^{3}$ hafizdahsyategmail.ac.id \\ Handphone: 0822-8214 - 7037
}

\begin{abstract}
Abstrak
Cloud storage is a development of cloud-based data storage, then Firebase provides services, one of which is Firebase storage, which is one of the technologies in the field. Cloud storage technology allows Android users to store data without requiring physical storage, specifically for Android users themselves the use of cloud storage will be very useful as an alternative storage media or backup media so that data is not easily lost. The design of cloud storage applications using Android-based firebase was developed beginning with analyzing needs, designing the appearance of applications, building applications, inputting program code, and testing applications. Output results to be achieved are the generation of cloud storage applications that can store various types of file extensions, are easy to use, and can run well on the Android platform. From this research, the results are obtained: first Cloud Storage technology is very useful as a data storage medium so that data is not easily lost, secondly making an Android application with Angular can be built with Cordova to run on the Android platform, thirdly Firebase has many features and services that can be used in the development of android applications, one of which is firebase storage.
\end{abstract}

Kata kunci: cloud storage, , Firebase, aplikasi android,Angular, Cordova

Keywords: cloud storage, android app, Firebase, Angular,Cordova

\section{Pendahuluan \\ 1.1 Latar belakang}

Saat ini, layanan penyimpanan data berbasis internet atau disebut cloud menjadi tren teknologi global. Pemanfaatan Internet of Things (IoT), big data dan advanced analytics ini membuat penggunaan dan kebutuhan penyimpanan data semakin meningkat. Cloud yang menawarkan skalabilitas tanpa batas menjadi sangat diandalkan. Cloud storage merupakan perkembangan teknologi penyimpanan data berbasis awan, lalu Firebase yang menyediakan berbagai macam layanan salah satunya yaitu Firebase storage, yang merupakan salah satu teknologi dalam bidang tersebut. Dengan teknologi cloud storage pengguna android dapat melakukan penyimpanan data tanpa memerlukan penyimpanan fisik, khusus untuk pengguna android sendiri penggunaan cloud storage akan sangat berguna sebagai media penyimpanan alternatif ataupun media backup agar data tidak mudah hilang. Penggunaan cloud storage juga dapat membantu pengguna android yang tidak memiliki dukungan kartu memori dan USB On The Go (OTG).

\subsection{Tujuan Penelitan}

Tujuan yang hendak dicapai dalam penelitian ini antara lain:

1. Memberikan alternatif media penyimpanan dengan memanfaatkan salah satu layanan Firebase yaitu Firebase Storage.

2. Mempermudah pengguna android dalam proses backup data dengan memanfaatkan layanan Firebase Storage.

\subsection{Manfaat Penelitian}

Dari penelitian yang dilakukan, diharapkan dapat mempunyai manfaat sebagai berikut:

\subsubsection{Manfaat Teoritis}

Penelitian ini diharapkan dapat memberikan sumbangan pemikiran yang cukup signifikan 
sebagai masukan pengetahuan atau literatur ilmiah yang dapat dijadikan bahan kajian bagi para insan akademik yang sedang mempelajari ilmu teknologi, khususnya mengenai pembuatan aplikasi cloud storage berbasis android sederhana dengan memanfaatkan layanan Firebase Storage.

\subsubsection{Manfaat Praktis}

1. Hasil penelitian ini secara praktis diharapkan dapat menyumbangkan pemikiran terhadap pemecahan masalah yang berkaitan dengan keterbatasan kapasitas penyimpanan fisik dengan memanfaatkan sistem Cloud Storage.

2. Hasil penelitian ini diharapkan menjadi acuan bagi calon pengembang aplikasi android agar dapat mengembangkan layanan Firebase dalam aplikasi yang akan dibuat.

\section{Tinjauan Pustaka}

\subsection{Pengertian Aplikasi}

Aplikasi atau perangkat lunak (Software) merupakan bagian yang tidak terpisahkan dari suatu sistem komputer, disamping keberadaan pengguna (Brainware), perangkat keras (Hardware) dan jaringan (Networking). Jika dilihat dari lingkungan pengembangannya, aplikasi dapat dibagi menjadi aplikasi berbasis dekstop, aplikasi berbasis web dan aplikasi berbasis mobile. (Prasetya, 2013)

\subsection{Penyimpanan Awan (Cloud Storage)}

Cloud storage merupakan sebuah aplikasi media penyimpanan awan yang berasal dari konsep komputasi awan, dimana dengan memanfaatkan teknologi ini dapat meningkatkan popularitas tidak hanya bagi sebuah organisasi tetapi juga kinerja individu. Lebih lanjut, Rajan and Shanmugapriyaa [2] menyatakan bahwa teknologi ini menyediakan ruang penyimpanan yang cukup besar untuk dapat digunakan dalam penyimpanan data/dokumen yang kita miliki serta memberikan manfaat terhadap akses data/dokumen kita secara mudah dari mana dan kapan saja. Saat ini ada beberapa teknologi penyimpanan awan yang dikembangkan meliputi Google Drive, Dropbox, Onedrive (sebelumnya SkyDrive), Box, dan lain-lain . (Gunadham, 2015)

\subsection{Firebase}

Firebase dianggap sebagai platform aplikasi web. Itu membantu pengembang membuat aplikasi berkualitas tinggi. Ini menyimpan data di Format JavaScript Object Notation (JSON) yang tidak digunakan permintaan untuk memasukkan, memperbarui, menghapus atau menambahkan data ke dalamnya. Ini backend dari sistem yang digunakan sebagai database untuk menyimpan data [4]. Layanan yang tersedia adalah:

1. Analisis Firebase

Ini memberikan wawasan tentang penggunaan aplikasi. Ini adalah aplikasi berbayar solusi pengukuran yang juga menyediakan keterlibatan pengguna Fitur unik ini memungkinkan pengembang aplikasi untuk memahami bagaimana pengguna menggunakan aplikasi ini. SDK memiliki fitur menangkap acara dan properti sendiri dan juga memungkinkan mendapatkan data khusus.

2. Firebase Cloud Messaging (FCM)

Ini sebelumnya dikenal sebagai Google Clouds Messaging (GCM), FCM adalah layanan berbayar yang merupakan solusi lintas platform untuk pesan dan pemberitahuan untuk Android, Aplikasi Web, dan IOS.

3. Firebase Auth

Firebase Auth mendukung penyedia login sosial seperti Facebook, Google GitHub, dan Twitter. Ini adalah layanan yang bias mengautentikasi pengguna yang hanya menggunakan kode sisi klien dan berbayar layanan. Ini juga mencakup sistem manajemen pengguna di mana pengembang dapat mengaktifkan otentikasi pengguna dengan email dan kata sandi masuk disimpan dengan Firebase.

4. Basis Data Real-time

Firebase menyediakan layanan seperti basis data waktu nyata dan backend. API disediakan untuk pengembang aplikasi yang memungkinkan data aplikasi disinkronkan klien dan disimpan di Cloud Firebase. Pustaka klien adalah disediakan oleh perusahaan yang memungkinkan integrasi dengan Aplikasi Android, iOS, dan JavaScript.

5. Penyimpanan Firebase

Ini memfasilitasi transfer file yang mudah dan aman terlepas dari jaringan kualitas untuk aplikasi Firebase. Ini didukung oleh Google Cloud Penyimpanan yang merupakan layanan penyimpanan objek yang hemat biaya. Itu pengembang dapat menggunakannya untuk menyimpan gambar, audio, video, atau lainnya konten yang dibuat pengguna.

6. Firebase Test Lab untuk Android

Ini menyediakan infrastruktur berbasis cloud untuk menguji Android aplikasi. Dengan satu operasi, pengembang dapat memulai pengujian aplikasi mereka di berbagai perangkat dan perangkat konfigurasi. Berbagai hasil tes seperti tangkapan layar, video dan $\log$ tersedia di Firebase console. Bahkan jika pengembang belum menulis kode uji apa pun untuk aplikasi mereka, Test Lab dapat berolahraga aplikasi secara otomatis, mencari crash. 
7. Pelaporan Kecelakaan Firebase

Laporan terperinci dari kesalahan dibuat di aplikasi. Itu kesalahan dikelompokkan ke dalam kelompok jejak tumpukan yang mirip dan triaged oleh keparahan. Fitur lainnya adalah: pengembang dapat mencatat acara khusus untuk membantu menangkap langkah menuju jatuh.

8. Pemberitahuan Firebase

Ini memungkinkan pemberitahuan pengguna yang ditargetkan untuk aplikasi seluler pengembang dan layanan tersedia secara bebas.

\subsection{Angular}

AngularJS adalah kerangka kerja aplikasi web open-source yang digunakan dalam mengembangkan aplikasi satu halaman sementara Apache Cordova memungkinkan pengembang membangun aplikasi seluler menggunakan Javascript, CSS dan HTML alih-alih menggunakan platform seperti antarmuka pemrograman aplikasi tertentu (API ') yang ada di iOS, Android atau Windows Phone. Kerangka ionik adalah kit pengembangan perangkat lunak sumber terbuka yang digunakan di untuk membuat aplikasi seluler hybrid. Itu dibangun menggunakan AngularJS dan Apache Cordova. (A Gupta, 2016)

Angular 2 adalah iterasi selanjutnya dari AngularJS Framework. Angular 2 Framework menjanjikan kinerja yang lebih baik dan menggunakan bahasa pemrograman TypeScript untuk pemrograman yang aman. Sementara Apache Cordova memungkinkan pengembang membuat aplikasi mobile menggunakan JavaScript, CSS dan HTML daripada menggunakan platform antarmuka pemrograman aplikasi spesifik (APIs ') seperti yang ada di iOS, Android atau Windows Phone. Ionic Framework adalah kit pengembangan perangkat lunak open source yang digunakan di untuk membuat aplikasi mobile hybrid. Dibangun dengan menggunakan AngularJS dan Apache Cordova. Ionic menyediakan pengguna dengan semua komponen, peralatan dan fungsi yang digunakan dalam pengembangan seluler asli - perangkat pengembangan perangkat lunak (SDKs). Pengembang bisa mendesain Aplikasi mereka menggunakan alat dan kode contoh yang disediakan oleh dokumentasi kerangka kerja dan bantuan situs web. Instalasi itu membutuhkan NodeJS dan npm yaitu pengelola paket bawaan untuk NodeJS, terlepas dari Windows, lingkungan Linux atau Macintosh. (DEWANTI \& GUNA PERMANA, 2017)

\section{Metode Penelitian \\ 3.1 Metode Pengembangan Sistem}

Metode pengembangan sistem yaitu waterfall. Metode air terjun (Waterfall) sering juga disebut model sekuensial linier (sequential linear) atau alur hidup klasik (classic life cycle). Model air terjun menyediakan pendekatan alur hidup terurut mulai dari analisis, desain, pembuatan kode program, pengujian, dan pendukung (support) atau pemeliharaan (maintenance). (Sukamto, 2013)

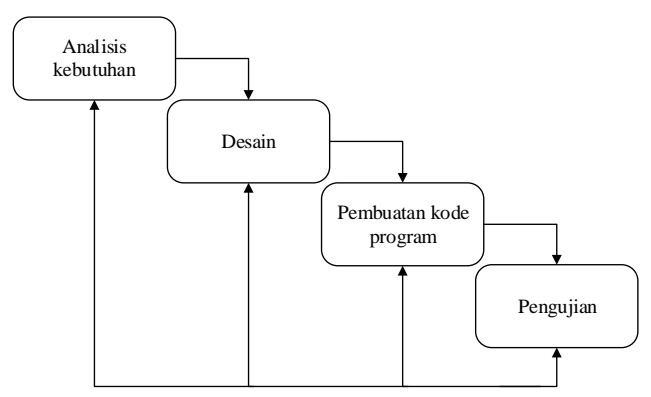

Gambar 1. Metode Pengembangan Sistem Waterfall

\subsection{Metode Perancangan Sistem}

Perancangan sistem menggunakan UML (Unifed Modeling Language), Use Case dan Activity Diagram.

\section{Pembahasan dan Hasil 4.1 Pembahasan}

Aplikasi Cloud Storage Menggunakan Firebase Berbasis Android adalah aplikasi yang dibuat sebagai media penyimpanan alternatif bagi para pengguna android Entry-Level. Aplikasi ini dibuat dengan menggunakan bahasa pemrograman typescript. Pembuatan aplikasi ini menggunakan Angular yaitu sebuah platform untuk mengembangkan front-end dari sebuah aplikasi web berbasis open source yang terhubung dengan layanan firebase storage. Build Apk menggunakan Cordova, dan dibantu dengan Visual Studio Code, Cmder, serta android Pie 9.0 (API level 28) sebagai alat bantu dalam mengembangkan aplikasi ini.

use case aplikasi cloud storage menggunakan firebase berbasis android dapat dilihat pada gambar.

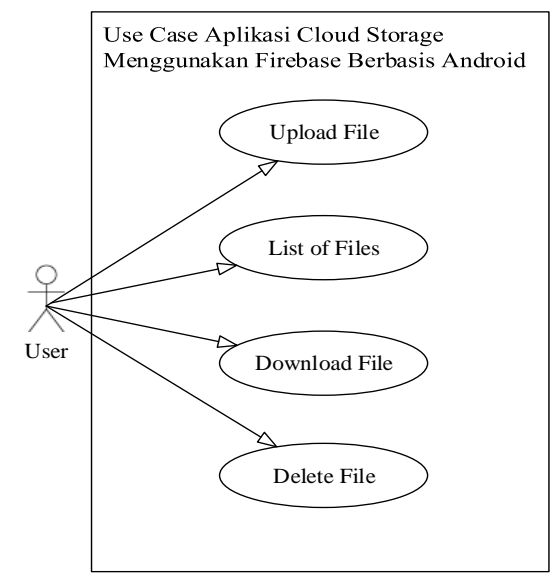

Gambar 2. Use Case Aplikasi Cloud Storage 
Rancangan UML Activity Diagram pada aplikasi cloud storage menggunakan firebase.

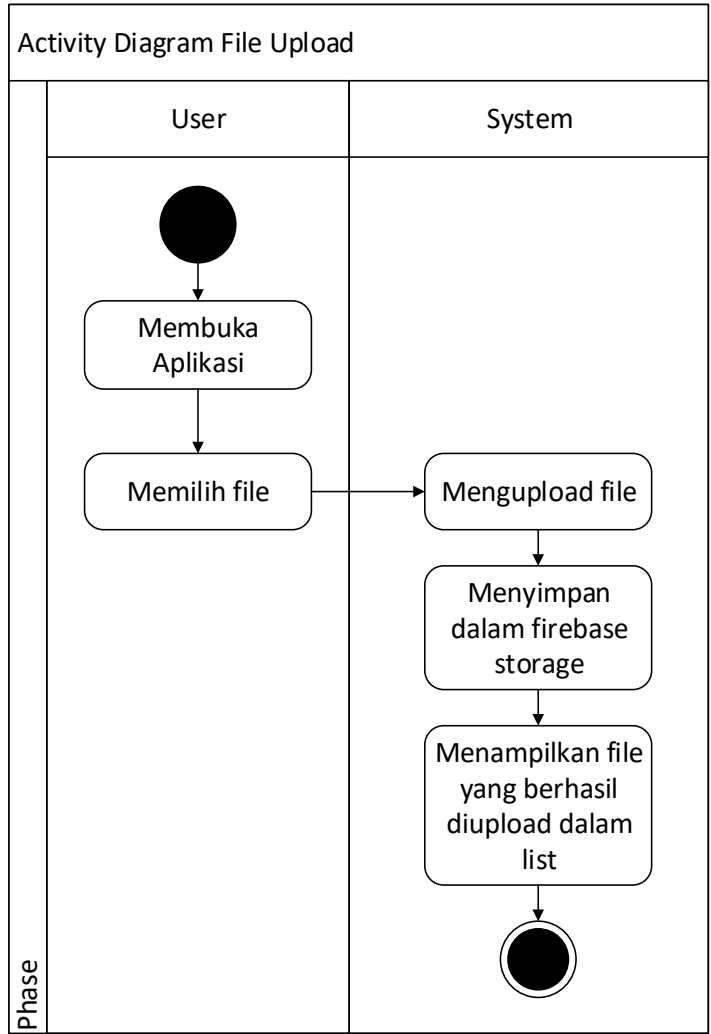

Gambar 3. Activity Diagram File Upload

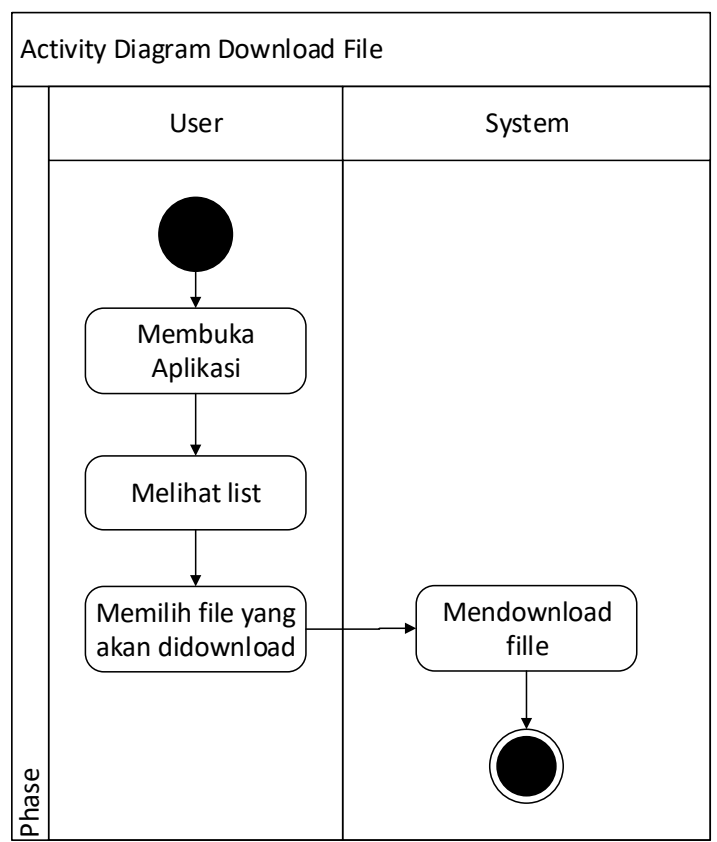

Gambar 4. Activity Diagram Download File

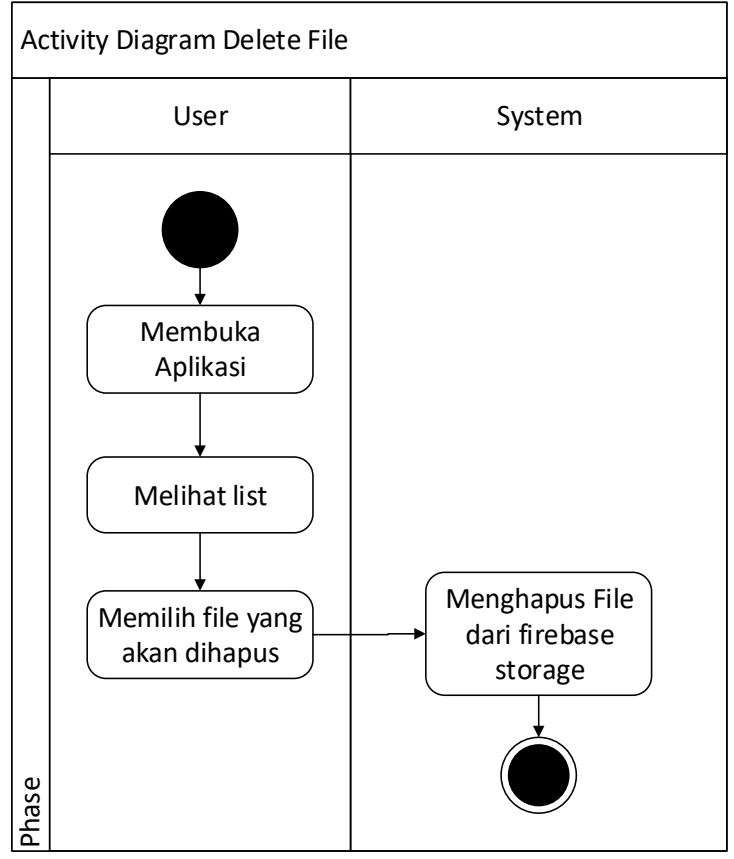

Gambar 5. Activity Diagram Delete File

Perancangan antarmuka merupakan proses penggambaran bagaimana sebuah tampilan (interface) dibentuk. Aplikasi ini dirancang dengan tampilan yang user friendly, sehingga diharapkan dapat mempermudah dalam penggunaan aplikasi ini.

\begin{tabular}{|l|c|}
\hline \multicolumn{2}{|c|}{ Title } \\
\cline { 2 - 2 } & Logo \\
\hline \multicolumn{1}{|c|}{ Description } \\
\hline Choose File & File name \\
\hline List of files & \\
\hline List 1 & Delete \\
\hline List 2 & Delete \\
\hline List 3 & Delete \\
Dst. & \\
\hline
\end{tabular}

Gambar 6. Rancangan Antarmuka Aplikasi 
Implementasi sistem/aplikasi, peneliti menggunakan Cmder dan Visual Studio Code yang digunakan untuk menginput kode program. Pembuatan aplikasi diawali dengan menginstall Node.js, Angular cli, Android JDK, Android SDK tools dan Cordova. Setelah semua sudah selesai diinstall dan terdeteksi dengan benar, peneliti membuat Angular project dengan mengetikan pada command line "ng new <nama project/aplikasi>". Berikut beberapa gambar penginputan kode dalam workspace yang sebelumnya telah dibuat.

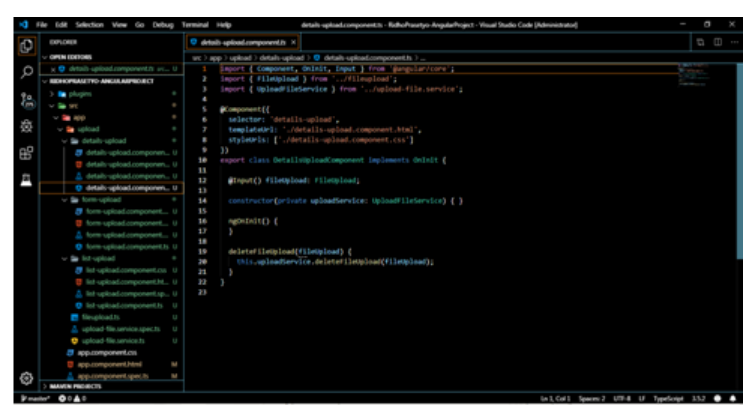

Gambar 7. Kode Program Pada detailsupload.component.ts

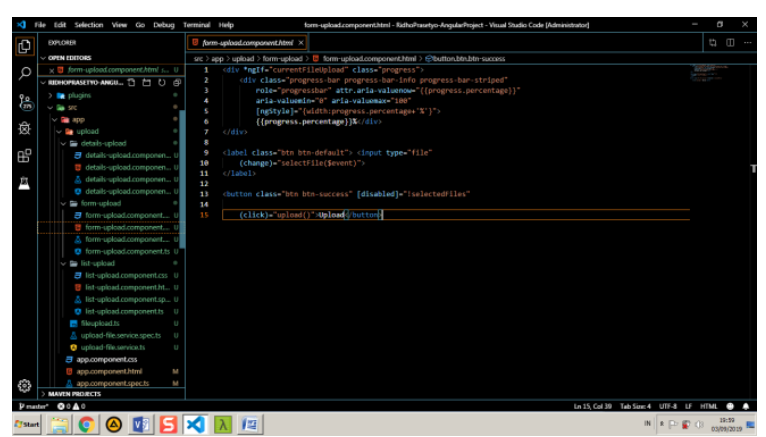

Gambar 8. Kode Program Pada formupload.component.html

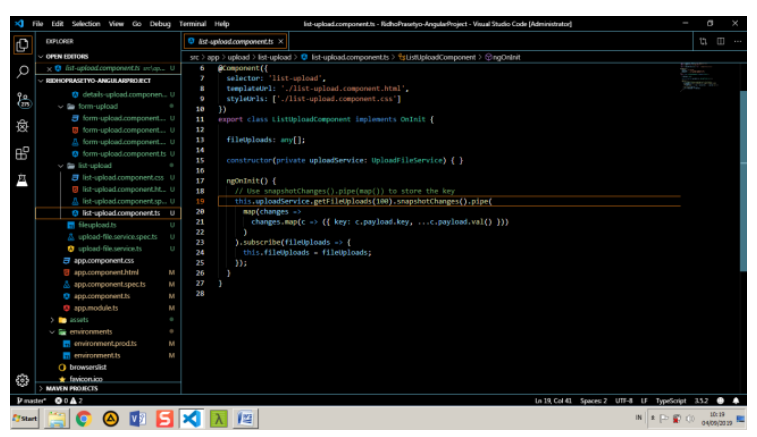

Gambar 9. Kode Program pada listupload.component.ts

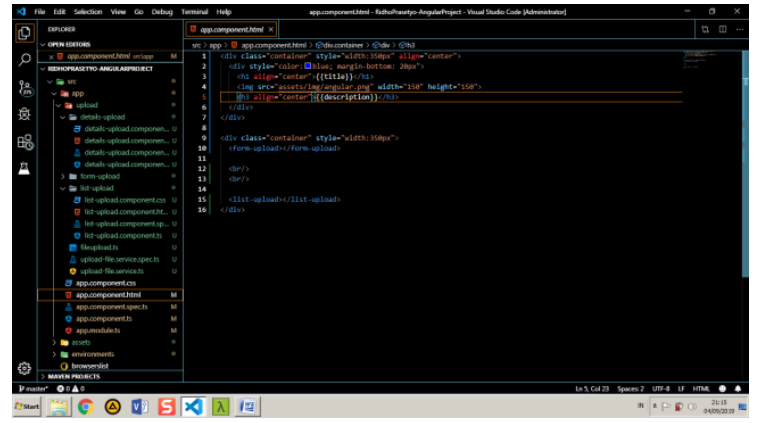

Gambar 10. Kode Program pada app.component.html

Untuk dapat terhubung dengan layanan firebase dibutuhkan firebaseConfig. Penempatan firebaseConfig berada pada src/app/environments/environment.ts

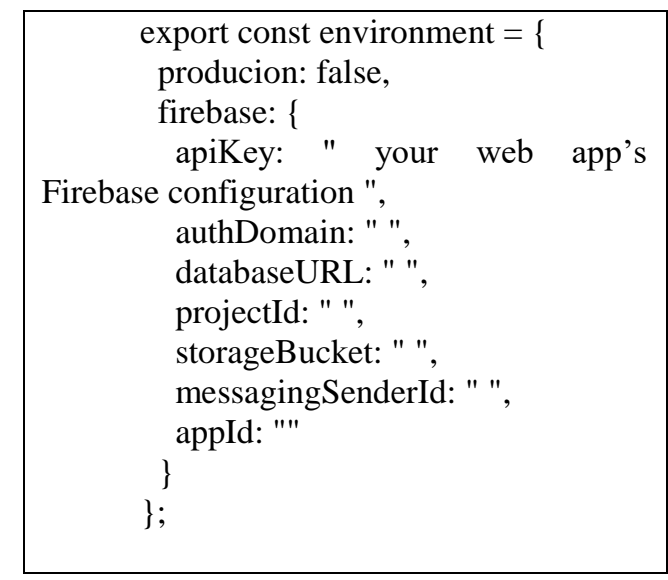

\section{Gambar 11. firebaseConfig}

Setelah perangkat lunak selesai diimplementasikan, pengujian dapat segera dimulai. Pengujian terlebih dahulu dilakukan pada setiap fungsi yang terdapat dalam aplikasi. Jika setiap fungsi dan prosedur tersebut selesai diuji dan terbukti tidak bermasalah, maka dapat segera diintegrasikan dan dikompilasi menjadi sebuah perangkat lunak yang utuh. Pada command line "ng serve <project>" atau "ng $s$ <project>", maka akan menampilkan Live Development Server. Pada tampilan cli akan terlihat seperti ini:

$\mathrm{D}: 1 * * * * * * * * * * *$-AngularProject $>$ ng serve

** Angular Live Development Server is listening on localhost:4200, open your browser on http://localhost:4200/**

Date: 2019-09-04T03:44:38.464Z

Hash: 1ede71022582b213d5e3

Time: $28979 \mathrm{~ms}$

chunk $\{$ main $\}$ main.js, main.js.map (main) $31 \mathrm{kB}$ [initial] [rendered]

$$
\text { chunk } \quad \text { \{polyfills\} polyfills.js, }
$$
polyfills.js.map (polyfills) $241 \quad \mathrm{kB} \quad$ [initial] [rendered] 
chunk \{runtime\} runtime.js, runtime.js.map (runtime) $6.22 \mathrm{kB}$ [entry] [rendered]

chunk \{styles\} styles.js, styles.js.map (styles) $15.6 \mathrm{kB}$ [initial] [rendered]

chunk \{vendor\} vendor.js, vendor.js.map (vendor) 4.16 MB [initial] [rendered]

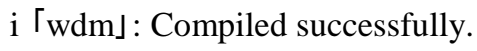

\subsection{Hasil}

Hasil penelitian merupakan hasil dari sebuah rancangan sistem yang sebelumnya di desain untuk membuat sebuah aplikasi cloud storage menggunakan firebase berbasis android.

Dibawah ini adalah tampilan aplikasi yang sudah dapat di gunakan.

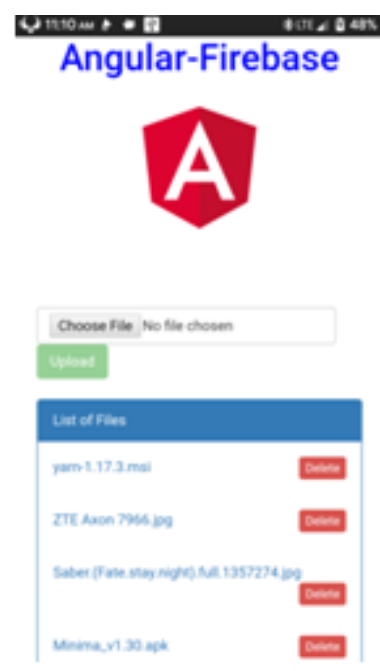

Gambar 12. Cloud Storage App

pengembangan aplikasi android, salah satunya adalah firebase storage.

\subsection{Saran}

Berdasarkan dari kesimpulan dan temuan dalam penelitian yang telah dilakukan maka peneliti memberi saran sebagai berikut :

1. Dalam pembuatan project aplikasi dengan Angular gunakan node_modules yang terbaru atau menyesuaikan dependencies dan devDependencies pada package.json untuk menghindari error.

2. Teliti dalam menginstall plugin npm dalam workspace.

3. Gunakan node.js LTS dan tidak sembarangan untuk menurunkan versi atau downgrade npm.

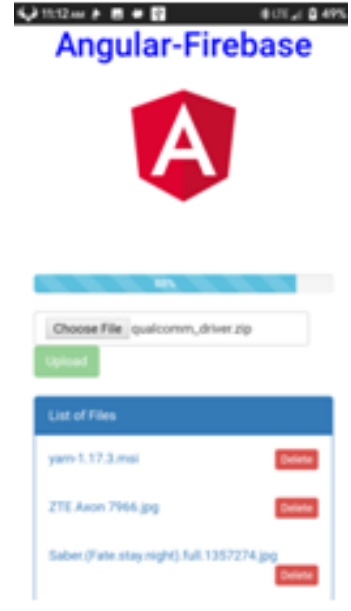

Gambar 13. Cloud Storage App (Upload Process)

\section{Kesimpulan dan Saran 5.1 Kesimpulan}

Media penyimpanan seperti cloud storage sangat dibutuhkan oleh pengguna smartphone android yang dalam kesehariannya memiliki banyak aktivitas menyimpan file dalam ukuran yang besar dan memiliki data-data penting. Dalam hal tersebut membutuhkan kapasitas penyimpanan lebih besar dan aman jika terjadi sesuatu pada smartphone android mereka, maka dari itu memanfaatkan media cloud storage adalah pilihan yang tepat sebagai media penyimpanan alternatif. Adapun kesimpulan yang didapat dari penelitian ini yaitu

1. Teknologi cloud storage sangat berguna sebagai media penyimpanan data agar data tidak mudah hilang.

2. dapat di build dengan Cordova agar dapat berjalan pada platform android.

3. Firebase memiliki banyak fitur dan layanan yang dapat digunakan dalam

4. Untuk generate.Apk dari workspace atau project folder, pastikan Environment Variables sudah disesuaikan dengan benar.

\section{Daftar Pustaka}

A Gupta, A. G. (2016). Hybrid Application Development using Ionic Framework \& AngularJS . International Journal of Innovative Research in Computer Science \& Technology (IJIRCST) ISSN: $2347-$ 5552, Volume 4, 62-64.

Chunnu Khawas, P. S. (2018). Application of Firebase in Android App Development-A Study. International Journal of Computer Applications

DOI: 10.5120/ijca2018917200. Volume 179, 46. 
DEWANTI, P., \& GUNA PERMANA, P. A. (2017). Pengembangan Aplikasi Hybrid Menggunakan Ionic 2 Framework dan Angular 2 . E-Proceedings KNS\&I STIKOM Bali, [S.l.]. ISSN 2460-8378, (hal. 396-400). Bali.

Gunadham, T. (2015). Potential of Cloud Storage Application as Knowledge Management Systems. International Journal of Innovation, Management and Technology, Vol. 6, No.2, 153-157.
Prasetya, D. D. (2013). Membuat Aplikasi SmartPhone Multiplatform. Jakarta: Elex Media Komputindo.

Rajan, R. A. (2012). Evolution of Cloud Storage as Cloud Computing Infrastructure Service. IOSR Journal of Computer Engineering (IOSRJCE) Volume 1, Issue 1 (May-June 2012), 38-45.

Sukamto, R. A. (2013). Rekayasa Perangkat Lunak Terstruktur dan Berorientasi Objek. Bandung: informatika. 